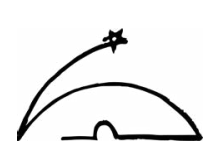

\title{
As políticas de transferência de renda e o desenvolvimento:
}

\section{o caso dos Kalapalo do Alto Xingu}

Marina Pereira Novo ${ }^{l}$

The main point is not whether to accept or deny the current model of development projects imposed by the state, but to transform it into what contemporary indigenous peoples want; not to get rid of development, but to indigenise it.

BANIWA, 2009

\section{Resumo}

Minha intenção neste artigo será tratar das políticas de transferência de renda enquanto uma das vertentes do movimento de expansão do capitalismo global, materializado em políticas de cunho "progressista" que afetam diretamente a vida e o cotidiano dos Kalapalo de Aiha. Por um lado, as políticas de transferência de renda se pautam em conceitos que desconsideram as especificidades dos povos indígenas e que incitam uma série de equívocos, que incidem sobre os processos de cadastramento e inclusão das famílias nos programas. Esses equívocos, por sua vez, geram uma série de cobranças e expectativas muitas vezes frustradas, tanto no que diz respeito ao Estado e seus representantes, quanto por parte dos Kalapalo. Por outro lado, ao serem incorporados aos circuitos "tradicionais" de circulação de bens, esses recursos passam a compor as redes que estruturam as relações de parentesco e aliança, dentro e fora das aldeias, em momentos cotidianos ou rituais.

Palavras-chave: Políticas de transferência de renda; desenvolvimento; dinheiro; Alto Xingu; Kalapalo

\begin{abstract}
In this article, I intend to discuss the cash transfer policies as one side of the capitalist global expansion. This movement materializes itself in "progressive" policies that affect the daily life of the Kalapalo people, from Aiha village. On one hand, cash transfer policies are based on concepts that disregard the indigenous peoples' specificities, and that lead to a series of misunderstandings, which affect the processes of enrollment and inclusion of families in the policies. These misunderstandings, or equivocations, to use Viveiros de Castro's conception, in turn, engender expectations, often frustrated, both toward the State and its representatives, as well as toward the Kalapalo. On the other hand, when these resources are incorporated into the "traditional" circuits of circulation of goods, they become part of the networks that structure kinship and alliance relationships, inside and outside the villages, in the daily life or in ritual moments.
\end{abstract}

Keywords: Cash transfer policies; development; money; Upper Xingu; Kalapalo

1 Pós-Doutoranda no Departamento de Antropologia Social da Universidade Estadual de Campinas (Unicamp). 
Os efeitos das políticas desenvolvimentistas ${ }^{2}$ - assim entendidas aquelas que são fruto de um processo econômico que "envolve a expansão da produção e do consumo e/ou o incremento dos padrões de vida" (FERGUSON, 2002: 234, tradução minha) - estão entre as principais preocupações atuais dos Kalapalo, assim como dos demais povos que compõem o Território Indígena do Xingu (TIX), no estado do Mato Grosso. Se, por um lado, os povos ali residentes buscam se aproximar das cidades, dos brancos $^{3}$ e se apropriar de seus conhecimentos ${ }^{4}$, por outro lado, esse processo é também o resultado das pressões exercidas por esses seres tão inventivos e perigosos, os brancos, e que promovem alterações na paisagem e nos regimes de chuvas, dos ventos, do fogo e dos rios. Minha intenção neste artigo será tratar das políticas de transferência de renda enquanto uma das vertentes desse movimento de expansão do capitalismo global, materializado em políticas de cunho "progressista" que afetam diretamente a vida e o cotidiano dos Kalapalo de Aiha.

Os Kalapalo vivem na porção sul do TIX, uma região também conhecida como Alto Xingu, um complexo sociocultural pluriétnico, composto por povos falantes de línguas pertencentes a diferentes troncos e famílias linguísticas ${ }^{5}$. Os Kalapalo contam com uma população total de aproximadamente 900 pessoas, distribuídas entre 12 aldeias, sendo a maior delas Aiha, localizada na margem direita do rio Culuene, com cerca de 250 pessoas. As questões aqui discutidas se baseiam em pesquisa realizada junto com os moradores de Aiha, entre 2006 e 2017, incluindo períodos em que estive na aldeia e conversas mantidas em outros espaços, de forma presencial ou virtual.

Ao longo de todos esses anos observei o aumento da quantidade de objetos disponíveis, incluindo enfeites "tradicionais" e industrializados (como missangas, fios de algodão e guizos metálicos). A disponibilidade de energia elétrica também aumentou e, consequentemente, o tempo que os moradores da aldeia passam assistindo à programação televisiva. Muitas casas passaram a dispor de eletrodomésticos, ferramentas, bicicletas, motos e carros, que alteraram a paisagem da aldeia, além da rotina e o ritmo de trabalho nas roças. Os novos meios de transporte também deixam muito mais barato e rápido o acesso às cidades do entorno do TI, ${ }^{6}$ facilitando a aquisição de produtos industrializados, como alimentos, roupas, novas ferramentas e eletrodomésticos. Isso sem contar os bens imateriais provenientes dos brancos, como é o caso das músicas, filmes, nomes...

2 As informações aqui apresentadas são o resultado de pesquisa realizada com financiamento da FAPESP (processo n. 2012/20200-1).

3 Forma mais comum como os povos do TIX se referem aos não indígenas.

4 Sobre a relação dos povos do TIX com as cidades, ver Novo (2018) e Horta $(2015 ; 2017 ; 2018)$.

5 Compõem o Alto Xingu povos de língua arawak (Mehináku, Wauja e Yawalapíti), karib (Kalapalo, Nahukua, Kuikuro e Matipu) e tupi (Kamayurá e Aweti), além dos Trumái, que falam uma língua considerada isolada.

6 O trajeto entre Aiha e Canarana (a cidade mais acessada pelos indígenas da região) incluía longos trechos fluviais (entre 5 ou 6 horas utilizando motores mais potentes, em viagens sem incidentes) e algumas centenas de reais para abastecer os barcos, além de um trecho terrestre, que dependia de carros fretados, totalizando algo como 8-9 horas de viagem. Hoje, a mesma viagem pode ser feita em poucas horas, atravessando um trecho curto do rio (não mais do que 40 minutos de barco) e depois seguindo em veículos particulares, sejam carros ou motos, o que também barateou o percurso. 
Se essas mudanças são o resultado da aproximação em relação ao "mundo dos brancos" e do aumento do acesso ao dinheiro, elas dificilmente podem ser analisadas apenas como uma resposta a potenciais necessidades impostas ou, ao menos, exacerbadas pela relação de "contato"7. A questão se mostra bastante mais complexa, quando se olha para as formas propriamente kalapalo de aquisição e circulação dos recursos e dos bens, considerando, por exemplo, que muitos deles são dados ou trocados com outras pessoas imediatamente após adquiridos, ou até mesmo abandonados ou esquecidos pouco tempo após sua aquisição.

$\mathrm{O}$ argumento que pretendo desenvolver é que, por um lado, as políticas de transferência de renda se pautam em conceitos que desconsideram as especificidades dos povos indígenas e que incitam uma série de equívocos, nem sempre controlados, (parafraseando Viveiros de Castro [2004]), e que incidem sobre os processos de cadastramento e inclusão das famílias nos programas. Esses equívocos, por sua vez, geram uma série de cobranças e expectativas muitas vezes frustradas, tanto no que diz respeito ao Estado e seus representantes, quanto por parte dos Kalapalo. Por outro lado, ao serem incorporados aos circuitos "tradicionais" de circulação de bens, esses recursos passam a compor as redes que estruturam as relações de parentesco e aliança, dentro e fora das aldeias, em momentos cotidianos ou rituais.

\section{Primeira série de equívocos: cadastramento e inclusão de "famílias indígenas"}

As políticas de transferência de renda, no Brasil, se ampliaram e ganharam muito destaque ao longo dos governos federais liderados pelo Partido dos Trabalhadores, especialmente entre os anos de 2003 e $2016^{8}$, o que incluiu sua extensão às populações indígenas do país. Atualmente, a principal dessas políticas - aquela que abrange a maior parte das famílias - é o Programa Bolsa Família (PBF), um programa de transferência direta de renda com condicionalidades, que atende famílias "pobres" - assim consideradas aquelas com renda mensal per capita entre R\$ 85,01 e R\$ 170 - e "extremamente pobres" - com renda mensal per capita de até R\$ 85 -, desde que devidamente cadastradas no Cadastro Único para Programas Sociais do Governo Federal (doravante Cadastro Único). O benefício é pago mensalmente pelo governo federal por meio da Caixa Econômica Federal (CEF) e pode ser sacado com um cartão magnético, emitido no nome do responsável familiar cadastrado. $\mathrm{O}$ saque pode ser feito em qualquer canal de pagamento vinculado à $\mathrm{CEF}$, incluindo as agências bancárias, terminais de autoatendimento, casas lotéricas, estabelecimentos comerciais ou agentes credenciados ao Caixa Aqui. Esse modelo de política trouxe uma série de avanços em relação às que a antecederam, pois, dentre outras razões, confere aos beneficiários a prerrogativa de escolha acerca dos usos dos recursos. Adicionalmente, em

$7 \quad$ Quando trato de "contato" aqui, não penso em uma relação totalizante nem inerte, na qual os povos indígenas se submetem passivamente a uma lógica colonial mais ampla e dominadora, mas como relações construídas e mantidas com distintas formas de alteridade, sejam elas humanas ou não humanas, indígenas ou não indígenas.

8 O governo, que substituiu aquele formado pela ex-presidenta Dilma Rousseff, vem reduzindo, paulatinamente, os recursos destinados às políticas sociais, incluindo as políticas de transferência de renda. 
termos econômicos, sua implementação significou a ampliação da renda das famílias, impactando positivamente nos índices de pobreza e desigualdade no país, como mostram diversos estudos realizados (CAMPELLO, 2013; JANUZZI; PINTO, 2013; SOARES et al., 2006; SOARES; RIBAS; OSÓRIO, 2007). Todavia, apesar desses avanços, os dois conceitos sobre os quais se ancora o PBF - família e pobreza - incitam uma série de equívocos, quando se trata de sua implementação junto aos povos indígenas.

Iniciarei tratando do conceito de família que é central na medida em que são elas - as famílias - as unidades às quais se destinam os benefícios, cujos valores variam em função de sua composição ${ }^{9}$. De acordo com o manual utilizado para treinamento dos cadastradores responsáveis pela inclusão das famílias no Cadastro Único, família é a

unidade nuclear composta por uma ou mais pessoas, eventualmente ampliada por outras que contribuam para o rendimento ou tenham suas despesas atendidas por ela, todas moradoras de um mesmo domicílio. Mesmo as pessoas que não sejam parentes, mas dividam as rendas e despesas de um domicílio são, para o Cadastro Único, uma família (BRASIL; MDS, 2016: 63).

Olhando para essa definição, percebe-se que os critérios adotados para identificar as famílias são a dependência econômica entre seus membros, além da coabitação em um mesmo "domicílio" ${ }^{10}$, independentemente da existência ou não de laços de parentesco entre as pessoas.

No momento do cadastro é preciso que os respondentes indiquem um "responsável familiar" em relação a quem será feito o cálculo dos demais componentes da família. Essa figura do responsável familiar, por sua vez, deve ter idade mínima de 16 anos e ser, preferencialmente, mulher (Ibid., 2016: 13). É em nome dessa pessoa que o benefício, caso aprovado, será concedido.

Apesar de não se deter aos laços de parentesco/consanguinidade, a definição de família - e, por extensão, de responsável familiar e de domicílio - utilizada pelo Cadastro Único possui algumas limitações quando se trata de famílias indígenas. A leitura de etnografias dos povos amazônicos já seria, por si só, suficiente para se ter uma dimensão da diversidade de arranjos "familiares" existentes na região, baseados em práticas de compartilhamento e convivência bastante distintas entre si e que em nada lembram uma pretensa "dependência econômica" entre seus membros. Mas antes de desenvolver esse argumento, pretendo mostrar como a noção mesmo de "responsável familiar", da forma como entendido pelo Cadastro Único, impacta no modo como são feitos os cadastros das pessoas de Aiha e, em consequência, na composição dos benefícios.

9 Sobre a composição do benefício, ver informações disponíveis no sítio eletrônico do Ministério do Desenvolvimento Social e Agrário (MDS): http://mds.gov.br/assuntos/bolsa-familia/o-que-e/beneficios. Acesso em 27 de julho de 2017.

10 A definição de domicílio utilizada pelo MDS se baseia naquela utilizada pelo Instituto Brasileiro de Geografia e Estatística (IBGE), sendo este um local de moradia "estruturalmente separado e independente, constituído por um ou mais cômodos" (BRASIL, 2012: 19). 
A primeira questão é a preferência por mulheres como responsáveis familiares, conforme orientações da política. Para os Kalapalo, colocar as esposas como responsáveis familiares não é, de antemão, uma escolha muito prática, já que elas nem sempre possuem documentação, pouco falam ou compreendem português, frequentam as cidades consideravelmente menos do que os homens e quando têm que resolver qualquer tipo de problema com o benefício, precisam ser acompanhadas por alguém (sempre um homem que fale português e que pode ser seu marido, irmão, filho, irmão do marido, a depender da disponibilidade). Ainda assim, quando fiz um levantamento dos benefícios de Aiha, mais da metade deles eram recebidos no nome de mulheres. Essa decisão é resultado, em parte, do desconhecimento das regras de funcionamento do programa que, apesar da indicação da preferência por mulheres, permite que o cadastro seja feito em nome do homem. Por outro lado, esses números também refletem o fato de que, em alguma medida, também os Kalapalo consideram que este seja um dinheiro "das mulheres", na medida em que, conforme me disseram muitas vezes, trata-se de um dinheiro que "quem tem filho recebe" e que serve "pra comprar algumas coisas pras crianças, caderno, bolsa [mochila]" 11 . Sendo um dinheiro "das crianças" ele se torna, por extensão, também um dinheiro das mulheres, suas mães, que são identificadas como suas principais cuidadoras.

Outra questão relacionada ao responsável familiar é a idade mínima exigida de 16 anos. Em Aiha, é comum que as mulheres se casem e tenham filhos pouco depois da reclusão pubertária, que dura entre um e dois anos após a menarca, o que significa que constituem uma "família" muito antes dos 16 anos. Ainda que, em teoria, o cadastro possa ser feito em nome dos maridos, considerando as questões expostas anteriormente, o que acontece na maior parte dos casos é a não realização do cadastro até que a esposa complete 16 anos e possa ser incluída como responsável familiar, fazendo com que essa "família" tenha que esperar, por vezes, alguns anos até que possa solicitar o benefício. Durante esse período, essa jovem mulher permanece "descoberta" financeiramente, em uma situação de potencial "vulnerabilidade" (para utilizar um termo da própria política), justamente nos primeiros anos de seu(s) primeiro(s) filho(s), momento bastante delicado de sua vida, especialmente nos casos daquelas mulheres que se mudam para as casas dos maridos.

Retomando a discussão acerca do conceito de família do Cadastro Único, pela descrição apresentada, é possível perceber que está ancorado em uma noção de compartilhamento de rendas e despesas bastante difícil de ser enquadrada no caso dos Kalapalo de Aiha, já que, na maior parte dos casos, nem mesmo existe qualquer "renda" ou mesmo "despesas" para além dos benefícios recebidos. Tratando de forma especulativa, nem mesmo a expansão desses termos - renda e despesas - de modo a incluir, por exemplo, os recursos disponíveis (alimentos e objetos), contribui para a delimitação dos limites das "famílias", deixando esses limites, ao contrário, ainda mais borrados. Mesmo que cada pessoa possa, em geral, ser identificada a uma

11 Essa percepção não é exclusiva dos Kalapalo, nem mesmo dos povos indígenas. Para afirmações semelhantes em outros contextos, ver Ahlert (2013), Ávila (2013), Pires (2009; 2013a; 2013b) e Verdum (2016). 
casa específica da aldeia, a circulação de pessoas e objetos/alimentos entre as casas é bastante significativa e fundamental para a criação e a manutenção das relações entre parentes. Assim, as crianças, muitas vezes, passam o dia circulando pelas casas de seus tios (irmãos e irmãs dos pais ou mães) ou avós, conforme a disponibilidade de comida em cada uma delas e podem, a depender da situação, morar (temporariamente ou não) na casa de algum desses parentes que resida em outras aldeias ou até mesmo em alguma cidade.

Além disso, por um lado, mesmo que separadas fisicamente, duas ou mais casas podem ser percebidas como contíguas, compartilhando a produção das roças e os espaços de cozinha. Por outro lado, mesmo residindo na mesma casa e compartilhando parte de seus recursos alimentares, distintas famílias gerem separadamente seus recursos financeiros, quando disponíveis: nesses casos, ainda que haja uma contribuição coletiva composta por recursos alimentares (que poderia fazer com que fossem considerados como parte de uma única família), estritamente nos quesitos "renda" e "despesas", os núcleos se percebem como autônomos e independentes. Também é muito mais comum que irmãos que morem em distintas casas compartilhem "rendas e despesas", se comparado a cunhados que residam juntos em um mesmo "domicílio".

Os casamentos poligâmicos (prática relativamente comum em Aiha) também criam algumas dificuldades na definição das famílias. Nesses casos, em geral, a solução adotada pelos cadastradores é cadastrar todas as esposas e seus núcleos familiares como dependentes da primeira esposa, o que pode impactar na composição do beneficio (já que há um limite na quantidade de benefícios que podem ser recebidos por família, no caso de famílias que superem a extrema pobreza), além de potencializar a existência de conflitos, na medida em que todo o benefício é pago em nome de uma única pessoa, identificada como "responsável familiar".

Essas situações tornam discricionária, na prática, a definição e o cadastramento de famílias indígenas, o que se agrava se consideradas as dificuldades linguísticas envolvidas no processo de cadastramento. Nos municípios que abrangem o Alto Xingu, as equipes de cadastro não dispõem de tradutores e os cadastros são feitos preferencialmente pelas mulheres que, com alguma frequência, são monolíngues ou pouco compreendem o português. Assim, se para os gestores e cadastradores se trata de um processo burocrático de cadastrar "famílias", sejam elas indígenas ou não, para os Kalapalo que solicitam o benefício há uma série de questões que precisam ser mobilizadas ao longo do processo para que o cadastramento ocorra de forma adequada. Os efeitos desses equívocos sobre o cadastramento e a composição dos benefícios podem ser geridos com maior ou menor sucesso pelos Kalapalo, a depender de seus conhecimentos e de sua desenvoltura em relação ao universo não indígena. Não à toa os conhecimentos de português e dos modos de vida dos brancos são tão valorizados pelos Kalapalo atualmente. ${ }^{12}$

12 Esse é apenas um dos muitos exemplos que poderiam ser citados de momentos em que os Kalapalo são exigidos desses conhecimentos. Sobre isso, ver Horta (2017; 2018); Novo (2018). 


\section{Segunda série de equívocos: uma política destinada aos "pobres"}

O segundo conceito central para as políticas de transferência de renda é a pobreza. Assim como família, esse conceito está cercado de equivocações que se manifestam, nesse caso, nas formas como meus interlocutores se relacionam com o Estado e seus representantes. No que diz respeito ao PBF e seu desenho, o critério de pobreza adotado para inclusão de famílias, sejam elas indígenas ou não indígenas, é a renda per capita, estando, portanto, exclusivamente relacionado à disponibilidade ou não de recursos financeiros. Nos primeiros anos após a implementação do PBF, o então Ministério do Desenvolvimento Social e Combate à Fome (MDS) ${ }^{13}$, ministério gestor do PBF, promoveu uma série de discussões junto a outros órgãos estatais e segmentos da sociedade civil, visando qualificar o cadastramento e inclusão de famílias indígenas no programa. Com esse intuito, foi desenvolvido um material utilizado no treinamento de gestores municipais e entrevistadores que contém questões de cunho mais geral a respeito da caracterização dos povos indígenas no país, passando por orientações sobre o processo de inclusão dessas populações nas políticas de transferência de renda, além de orientações específicas sobre o preenchimento dos questionários. Dentre os pontos levantados nesse material, há uma indicação de que nem todas as famílias indígenas devem ser cadastradas, "somente aquelas [...] que passam por situações de insegurança alimentar e nutricional e vulnerabilidade social” (BRASIL; MDS, 2015: 27). Para tanto, o manual orienta os gestores municipais que desenvolvam ações de consulta prévia aos povos indígenas, de forma a garantir seu direito de decisão sobre "seus destinos e participar ou não de políticas públicas disponíveis para o conjunto da sociedade brasileira" (Ibid.: 20). O manual indica também que

\footnotetext{
(...) muitas vezes, os critérios utilizados para definição de situações de pobreza e extrema pobreza nos programas sociais não se aplicam a esses povos. A inclusão equivocada de famílias indígenas em programas sociais pode trazer consequências desagregadoras na organização social desses povos. (Ibid.: 27).
}

Apesar das orientações contidas no manual de treinamento indicarem que o critério de renda nem sempre é o mais adequado para medir a situação de pobreza das famílias indígenas, considerando o formato do cadastro e a forma atual de seleção de famílias, não existe qualquer especificação ou mesmo possibilidade para que, na prática, outros critérios não monetários sejam considerados. Assim como não há abertura para ações desse tipo, em Aiha também nunca houve nenhuma atividade de consulta prévia, conforme recomendado no manual de cadastramento. Pelo contrário, apesar das orientações, o que se observa nos municípios que abrangem a região do Alto

13 Após o processo de afastamento da presidenta Dilma e a posse do seu vice, Michel Temer, esse ministério foi transformado em Ministério do Desenvolvimento Social e Agrário, mantendo-se sua sigla inicial. 
Xingu é um grande esforço das equipes de assistência social no sentido de "aumentar a cobertura" dos cadastros, o que significa cadastrar a maior quantidade possível de famílias, incluindo aí as famílias indígenas, sem que haja qualquer preocupação com a qualidade das informações repassadas às famílias e às comunidades. Cadastrar as famílias indígenas é bastante interessante para as gestões municipais, considerando que elas compõem parte importante do contingente populacional dos três municípios que abrangem a região do Alto Xingu (Canarana, Querência e Gaúcha do Norte), e seu cadastro contribui para o cálculo do Índice de Gestão Descentralizada Municipal (IGD-M), utilizado para repasse valores do governo federal para as gestões municipais.

Uma vez cadastradas, a seleção das famílias que serão contempladas com o benefício de PBF está condicionada exclusivamente ao cumprimento do critério de renda, da mesma forma como ocorre com todas as demais famílias cadastradas, independentemente de suas especificidades. A seleção é feita de forma automatizada pelo governo federal e leva em conta o percentual de cobertura da estimativa oficial de famílias pobres no município (cálculo feito utilizando os dados produzidos pelo Instituto Brasileiro de Geografia e Estatística - IBGE), a quantidade de famílias com cadastros habilitados em cada município e a disponibilidade orçamentária e financeira, segundo a Lei Orçamentária Anual em vigor. No caso de haver mais famílias habilitadas no município do que a estimativa de famílias pobres, são priorizadas as famílias indígenas, quilombolas e que possuam em sua composição crianças em situação de trabalho infantil, desde que cumpram os critérios para acesso ao programa (BRASIL; MDS, 2008). Na prática, isso significa que as famílias indígenas que cumprem os critérios de renda são automaticamente incluídas na folha de pagamento do PBF, o que nem sempre ocorre com as famílias não indígenas.

Uma vez que o PBF tem como objetivo a superação da situação de pobreza, a avaliação da situação global de cada um dos povos indígenas que possuem famílias cadastradas seria um passo importante na caracterização dessas famílias e de suas condições de vida e, consequentemente, para a identificação de situações de vulnerabilidade que estejam ligadas a questões que estão além da presença ou ausência de renda. Se, para o Estado, a pobreza é definida exclusivamente com base em critérios monetários, para os Kalapalo, o conceito de pobreza possui outros significados relacionados à capacidade de viver adequadamente entre parentes.

Em diversos momentos da pesquisa, conversando comigo, meus anfitriões se referiam a si mesmo como pobres e essa afirmação sempre me provocava alguma confusão. Sei do orgulho que os alto-xinguanos sentem de sua "cultura", materializada nas festas que realizam e enfeites que possuem - conferindo-lhes uma certa condição de "riqueza", portanto, sob meu ponto de vista -, além do fato de que, todas as vezes que se comparam com outros povos indígenas, ressaltam a qualidade de suas condições de vida e, mais do que tudo, das terras em que vivem. Não há dúvidas de que o fato de estarem em um território demarcado e bastante preservado (apesar das pressões exercidas pelo agronegócio, responsável pela devastação das matas e das cabeceiras dos rios que abastecem as aldeias, localizadas fora do TIX) lhes confere uma condição relativamente confortável, especialmente se comparada àquela de outros povos cujas terras não estão demarcadas, 
são muito restritas, ou já tenham sido devastadas. Quando questionados a esse respeito, meus interlocutores diziam que pobre é jatsi, "coitado", "a pessoa que não tem algumas coisas, que fica com vontade de ter alguma coisa e não tem" (grifos meus), "a pessoa que não tem ninguém pra cuidar dela". Jatsi também era a forma como eles se referiam aos seus ancestrais, por "não possuírem muitos enfeites" e aos indígenas alto-xinguanos que moram nas cidades, dizendo que estes ficam "pedindo trocadinho", pois nunca teriam dinheiro suficiente para se manterem confortavelmente. Distintamente, portanto, da "pobreza" que o governo federal pretende combater por meio das políticas de transferência de renda, para os Kalapalo, ainda que haja alguma referência a dificuldades decorrentes da falta de dinheiro, esse conceito parece muito mais relacionado à ausência de relações adequadas entre as pessoas, à ausência - ou a corrupção - do parentesco.

Para compreender essa afirmação, é preciso esclarecer, de antemão que, para meus anfitriões, cabe aos parentes - especialmente os mais próximos - cuidar dos seus, o que se manifesta por meio do compartilhamento (ijatitselü) de alimentos, enfeites ou outros objetos, de modo a suprir os desejos daquele que é cuidado. Esse "desejo" de que trato é uma tradução dos termos iti e hogu, que indicam a vontade ou a necessidade de algo, sem que haja uma distinção de gradiente: muita vontade ou pouca vontade, desejo e necessidade são expressos da mesma maneira. Não se trata do desejo do "homem econômico", baseado no interesse individual. Talvez, penso, seja mais adequado pensar nesse desejo enquanto vetor de um movimento em direção às cidades, aos objetos, aos parentes, e que, nesse sentido, se aproximada da noção de desejo enquanto produção, conforme discutido por Deleuze e Guattari (2010) ${ }^{14}$. Assim é que, para os Kalapalo, é o desejo que possibilita tanto a criação e manutenção das relações existentes - quando devidamente suprido quanto o rompimento delas - no caso da incapacidade ou, ainda pior, da falta de disposição para que os objetos desejados sejam disponibilizados. Retomarei essa discussão adiante, mas o que vale reter nesse momento é que a condição de pobreza, para eles, está diretamente relacionada à incapacidade de suprir os próprios desejos e os de outrem, o que ganha novas nuances, quando se trata de objetos industrializados.

Se a condição de pobreza está, aqui, associada à ausência de cuidados, penso ser essa também a chave para pensar na forma como os Kalapalo se colocam frente às políticas de transferência de renda, destinadas aos "pobres". Ainda que não saibam identificar precisamente de onde vem o dinheiro dessas políticas (a que se referem genericamente como bolsas), nem por isso há, por parte dos Kalapalo, qualquer tipo de questionamento sobre sua legitimidade. Pelo contrário, mesmo sem expressar claramente uma noção de "direito", cobram dos agentes estatais (sejam representantes da Funai, da assistência social dos municípios e até mesmo profissionais de saúde que atuam nas aldeias) sua inserção nessas políticas e buscam de todas as formas garantir o acesso aos benefícios. Mas, novamente, não se trata apenas da vontade de ganhar dinheiro para adquirir objetos para uso pessoal fomentada por uma espécie de ganância, conforme uma parte

14 Faço essa sugestão inspirada na discussão feita por Horta (2018) sobre os indígenas xinguanos que moram em Canarana. 
significativa dos brancos que circulam pelas cidades do entorno do TIX (ou mesmo dos altos escalões do governo...) parece supor. O dinheiro das bolsas, assim como o dinheiro das aposentadorias e outros benefícios sociais (e, por extensão, também dos objetos industrializados adquiridos com eles), é fundamental para a garantia do bem-estar das pessoas de Aiha, mas isso só se torna possível por meio de sua circulação, não seu acúmulo, questão a que voltarei mais à frente.

Assim, por um lado, o aumento dos recursos ampliou o acesso e a frequência com que os Kalapalo estão nas cidades (seja para receber os benefícios, seja para gastar os recursos disponíveis), provocando, em alguma medida, uma expansão dos desejos (e também da dependência) de bens industrializados ${ }^{15}$. Mas, por outro lado, a circulação dessas mercadorias na aldeia, e mesmo entre as aldeias, se relaciona aos modos propriamente kalapalo de compartilhamento e troca, motivados por uma lógica que envolve questões ligadas ao parentesco, aos cuidados e a uma noção particular de bem viver ${ }^{16}$.

Sendo o dinheiro fundamental para a manutenção das redes de parentesco, as políticas de transferência de renda é que tornam isso possível à maior parte das pessoas de Aiha, até mesmo aquelas que possuem pouco domínio do português e dos "conhecimentos dos brancos". Dessa forma, a afirmação de que são pobres no contexto das relações com os não indígenas, especialmente os representantes do Estado, ganha ainda outras nuances. Isso porque os brancos são identificados como "fontes institucionalizadas [e, talvez, inesgotáveis] de recursos" (FRANCHETTO, 2007: 19), na medida em que são os donos (oto) do dinheiro e dos objetos industrializados. A noção de dono aqui remete a uma espécie de "razão de existência", ou de origem, e que lhes confere a prerrogativa e, mais ainda, o dever de fazer circular suas posses. ${ }^{17}$ Nessa relação, ao se dizerem pobres para os brancos, os Kalapalo estão se colocando em uma posição de "extratores" de recursos: afinal, se cabe àqueles que têm os objetos distribuí-los aos demais, àqueles que não os possuem, é preciso enfatizar todo o tempo aquilo que não se tem e esperar que os brancos assumam e cumpram com seu papel de donos dos objetos.

Para além dessa ênfase, é bastante comum ouvir os Kalapalo se referirem aos representantes do Estado, ONGs, ou mesmo outros não indígenas considerados por eles como "autoridades" utilizando termos de parentesco como papai, mamãe, vovô e vovó. Nesses casos, os termos utilizados parecem fazer menos referência a uma relação de parentesco no sentido estrito do termo - e, como já apontou Vanzolini (Id., 2015: 269), “chamar por um termo de parentesco não significa reconhecer como parente" - do que à explicitação do tipo de expectativa que possuem em relação à figura a quem fazem referência. Ao se colocarem como "filhos", o que os Kalapalo

15 Como discuto alhures (NOVO, 2018), há uma relação intrínseca entre ver e desejar alguma coisa. Dessa forma, a presença das pessoas nas cidades contribui para o aumento dos desejos, pois aumenta também o contato visual com uma quantidade incontável de objetos.

16 Bem viver não é um conceito nativo local, mas emprestado por mim de outros contextos e etnografias por considerar adequado para a argumentação que faço.

17 Desenvolvi essa discussão sobre a noção de dono em Novo (2018). Sobre isso, ver também Barcelos Neto (2008), Guerreiro (2015), Vanzolini (2008; 2015; 2018). 
estão fazendo é criar uma assimetria, se deixando "domesticar", em alguma medida, como uma forma de "reclamar atenção e generosidade" (FAUSTO, 2008: 333), que, entendo, seria a forma possível do Estado demonstrar cuidado, conforme discutido anteriormente.

Novamente, essa forma de relação pressupõe um comportamento ético adequado, que inclui não apenas o cuidado, mas também (e aqui, talvez, principalmente), a generosidade - o que se espera dos "pais" e "avós". Sugiro aproximar esse comportamento daquilo que os Kanamari chamam de "alimentar", ou seja, um ato que "cria ou transmite uma relação assimétrica entre aquele que alimenta e aquele que aceita ser alimentado" (COSTA, 2016: 84, tradução minha), e que "cria ou perpetua uma necessidade pela pessoa que alimenta [...], que podemos caracterizar como uma "dependência"” (Id., 2013: 476). Ao se afirmarem pobres e se colocarem como "filhos" frente aos órgãos ou representantes estatais, os alto-xinguanos estão, por um lado, se colocando em uma posição submissa às "forças do Estado", mas, ao mesmo tempo, fazendo uma espécie de domesticação às avessas, se utilizando de suas estratégias sutis de sedução para "xinguanizar" o mundo à sua volta; ou ao menos uma parte dele. Se, nas aldeias, cabe aos pais - e àqueles que são os donos dos recursos - satisfazer os desejos dos filhos - ou de quem manifeste seu desejo por eles -, cabe ao Estado e seus representantes satisfazer os desejos de seus "filhos", os alto-xinguanos, fornecendo-lhes os recursos necessários para a manutenção de sua vida ou mais especificamente, seu "bem viver". Todavia, os brancos nem sempre correspondem às expectativas e se mostram egoístas e gananciosos, se afastando tanto quanto seria possível dos ideais de comportamento das "pessoas de verdade" (kuge).

\section{Terceira série de equívocos: as condicionalidades}

Uma vez incluídas no Bolsa Família, as famílias se comprometem a cumprir com alguns compromissos de atendimento às políticas de saúde e de educação (as chamadas "condicionalidades"), além de precisarem atualizar seus cadastros a cada período máximo de 24 meses, para que se mantenham vinculadas ao programa. $\mathrm{O}$ modelo de políticas de transferência de renda com condicionalidades foi implementado mundialmente em meados da década de 1990, sendo os mais conhecidos e abrangentes em termos de cobertura, o Programa Oportunidades do México e o Programa Bolsa Família, no Brasi ${ }^{18}$. As condicionalidades são entendidas pelo poder público como uma forma de ampliar "o acesso aos direitos sociais básicos para as famílias que recebem o benefício financeiro", tendo como objetivo "associar a renda ao acesso das crianças e adolescentes à educação básica, à sua permanência na escola e ao acesso dos grupos familiares à rede de saúde" (CUNHA, 2009: 339).

O descumprimento das condicionalidades (ou ao menos a ausência de informação sobre o

18 De acordo com Fonseca (2006: 7, tradução minha) “estes programas foram apresentados como uma inovação no âmbito do combate à pobreza, por não adotarem o modelo de seguro social - trabalho -> contribuições -> benefícios -> serviços - e por romperem com a tradição das bolsas de alimentos". Para uma apresentação detalhada dos programas na América Latina e em outras partes do mundo, ver Fiszbein (2009). 
cumprimento das mesmas) tem como efeito uma aplicação gradativa de penalizações, começando com uma advertência, e chegando até o cancelamento do benefício. Nesses casos, a legislação vigente orienta que as equipes de assistência social façam o acompanhamento das famílias, a fim de garantir que o descumprimento não seja decorrente de uma situação de extrema vulnerabilidade (BRASIL; MDS, 2017).

No contexto de Aiha, esse acompanhamento da assistência social não ocorre - ao menos não no espaço da aldeia, onde deveria acontecer. Possivelmente, a distância e a falta de profissionais qualificados são decisivos para essa ausência de acompanhamento, que resulta, na prática, na punição unilateral das famílias indígenas, que sofrem os efeitos sobre seus benefícios. Sem o devido acompanhamento, torna-se impossível a identificação de problemas na oferta dos serviços de saúde e de educação (já que nem sempre há a infraestrutura ou os materiais necessários), ou ainda, no fluxo de informações. Em muitos casos, as famílias cumprem com as condicionalidades, mas as informações apenas não são devidamente registradas nos sistemas, por dificuldades de comunicação entre os profissionais responsáveis pelos serviços e os gestores. Mesmo fazendo o acompanhamento mensal de saúde das crianças, por exemplo, é comum acontecer das famílias de Aiha serem cobradas desses dados diretamente pela gestão municipal do PBF e precisarem se deslocar até as cidades carregando consigo um papel com todas as medidas anotadas, gerando gastos inesperados com deslocamento e manutenção na cidade, que muitas vezes superam os valores recebidos.

Outro problema com as condicionalidades, especificamente entre povos indígenas, é que elas desconsideram as práticas tradicionais. Por exemplo, no que diz respeito às condicionalidades de saúde, as mesmas preconizam exclusivamente o acompanhamento das crianças pelos profissionais de saúde biomédicos, sendo que as famílias nem sempre reconhecem a real necessidade desse tipo de acompanhamento, que não lhes parece resultar em efeitos práticos no que diz respeito à saúde das suas crianças.

Retratando especificamente o caso de Aiha no que diz respeito às condicionalidades de educação, a frequência obrigatória à escola - que, em geral, é considerada positiva pelos pais -significa, em alguns casos, a necessidade de deixar de participar de atividades cotidianas fundamentais para a (re)produção da vida local, como o trabalho nas roças ou as atividades coletivas. Os períodos de reclusão pubertária também são críticos, já que são os momentos privilegiados de "aprendizado da cultura" (como dizem os próprios Kalapalo), mas são desconsiderados na política de acompanhamento das condicionalidades: caso o jovem e seus pais optem por sua ausência temporária da escola para que permaneça em reclusão "completa" (que pode durar entre alguns meses e alguns anos), o benefício relacionado a este jovem sofre as referidas repercussões.

Adicionalmente, o próprio esquema de registro da frequência escolar exigido é problemático, na medida em que a escola local, por ser diferenciada, de acordo com a própria legislação federal vigente, possui também um calendário diferenciado que respeita os períodos de festas 
na aldeia. Entretanto, para o acompanhamento das condicionalidades, o registro de frequência deve ser feito seguindo o calendário das escolas regulares ${ }^{19}$.

Além das questões apontadas anteriormente, outro fator importante que interfere no cumprimento e acompanhamento das condicionalidades é a falta de informação dos beneficiários, que muitas vezes não entendem o que lhes é solicitado e desconhecem o processo de gestão e fiscalização do programa e, por medo de perder os benefícios, se deslocam para as cidades com muito mais frequência do que seria necessário.

Assim, para além do fato de não haver qualquer avaliação acerca do processo de inclusão dos Kalapalo por parte das gestões municipais e federais, não há nem mesmo a garantia da oferta de serviços de educação e saúde adequados (já que faltam equipamentos, medicamentos e materiais), obrigando os Kalapalo a cumprir com condicionalidades que não dialogam com as suas próprias aspirações nem realidades. Neste sentido, tem-se, em teoria, que "as condicionalidades podem ser entendidas como reforço de direitos de cidadania, reforço do direito de acesso já previsto na Constituição Federal" (CUNHA, 2009: 340), mas, na prática, elas se tornam uma obrigação dos beneficiários, muitas vezes sem nenhum sentido efetivo, e que acabam por desrespeitar o direito constitucional dos indígenas a ações e serviços diferenciados.

Considerando essas questões, pode-se dizer que, apesar da concepção do PBF apontar para sua "multissetorialidade", agregando a complementação da renda ao acesso aos direitos e às ações articuladas (conforme definição disponível no sítio eletrônico do ministério gestor do programa [BRASIL; MDS, 2017]), efetivamente, ao menos no que diz respeito aos povos indígenas, o programa acaba por se caracterizar unicamente como uma ação redistributiva universalista, sem que se tenha qualquer preocupação com o reconhecimento das especificidades de seu público alvo ${ }^{20}$.

Levando essa análise às últimas consequências, até mesmo os efeitos do PBF sobre a renda dos indígenas podem ser questionados (ainda que eu não possua dados estatísticos a esse respeito), na medida em que, da forma como a política é efetivada, os gastos exigidos dos beneficiários para sacar os benefícios, e para atualizar constantemente os cadastros, impactam significativamente nos valores recebidos. Soma-se a isso o fato de que, tanto o acesso à renda quanto à educação formal - e mesmo a "entrada no mercado de trabalho" - preconizados pelo programa, são temas altamente controversos no contexto dos povos indígenas, e que podem justamente gerar efeitos negativos sobre estes povos, já que impulsionam as pessoas cada vez mais para fora de suas comunidades de origem, com destino às cidades, gerando efeitos importantes sobre a socialidade na aldeia e também na vida dessas pessoas que se deslocam para as cidades ${ }^{21}$.

19 Esse é um dos inúmeros exemplos das divergências e incongruências que apontam para a inexistência de uma figura única e unívoca que possa ser chamada de "Estado".

20 Utilizo aqui os conceitos de redistribuição e reconhecimento conforme descritos por Fraser (2003).

21 Sobre a relação dos xinguanos com as cidades ver Novo (2018) e Horta $(2015 ; 2017 ; 2018)$. 


\section{Bolsa Família: um "dinheirinho patikula"}

Apesar dessas dificuldades enfrentadas pelas famílias para garantir seu cadastramento e a manutenção de seus benefícios, o que se observa em Aiha é uma procura intensiva das pessoas pelos recursos provenientes dos benefícios sociais. Ainda que isso possa ser lido como uma espécie de ingenuidade dos Kalapalo frente ao movimento avassalador do desenvolvimentismo capitalista, essa não me parece ser uma leitura satisfatória do que se passa. Ao contrário, minha sugestão aqui é analisar o modo como meus interlocutores se apropriam desses recursos e dos objetos com ele adquiridos e os fazem circular, desafiando a lógica da propriedade particular e dos direitos individuais que perpassam as regras de inclusão e permanência nos programas. Esse modo talvez seja uma das formas que a "resistência ao aparelho de captura capitalista pode tomar em seu mundo" (VANZOLINI, 2018: 328).

Os recursos provenientes das políticas de transferência de renda possuem uma peculiaridade se comprados aos demais recursos financeiros acessados pelos Kalapalo, pois compreendem um acesso "individual/familiar", ou "patikula"22", como dizem, em contraposição aos recursos coletivos - o dinheiro ou as coisas "da comunidade", katutolo engü (“coisas de todos"), ou seja, verbas e produtos industrializados advindos de projetos, visitantes, pesquisadores e das associações indígenas. Essa forma específica de relação entre as pessoas e "suas" coisas - o patikula-, também não se configura em um regime de propriedade privada, na medida em que, quando se observa a maneira como circulam, é possível perceber que o que importa de fato são muito mais as relações estabelecidas entre as pessoas (por meio das coisas), e não as coisas em si, como bem apontou Vanzolini (2018: 334). E se essa afirmação vale para os objetos ditos “tradicionais", vale também para os objetos "de branco".

Para compreender melhor as implicações dessa noção para a circulação de coisas, é primeiro preciso olhar para a figura dos donos. No Alto Xingu todas as coisas têm um dono, que é como os Kalapalo - e os demais povos de língua karib da região - traduzem o termo oto (cujos equivalentes para outros povos são wekeho, para os Wauja, wekehe para os Mehinaku, itat para os Aweti, wikiti para os Yawalapiti, yar para os Trumai) ${ }^{23}$. Assim, por exemplo, os feitiços possuem donos (kugihe oto), as histórias possuem donos (akinha oto), assim como as rezas (kehege oto), os cantos (eginhoto), as festas e os objetos e, como já apontei anteriormente, cabe a esses donos a prerrogativa e a obrigação de fazer circular suas "posses". A generosidade, "qualidade mais valorizada por todos os povos indígenas das Américas” (PERRONE-MOISÉS, 2016: 6), é característica fundamental do ideal de pessoa para os Kalapalo, e os modos de circulação das coisas (seja por meio das trocas, roubos, empréstimos, compras e vendas) são marcadores importantes dos tipos de relações que

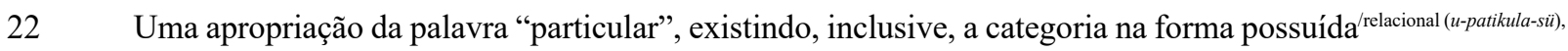
referindo-se a algo possuído por um indivíduo

23 Ainda que todos esses termos sejam traduzidos como dono, seus usos podem apresentar variações. Para discussões sobre os usos do conceito de dono entre povos alto-xinguanos, ver Viveiros de Castro (1977), Vienne e Allard (2007), Guerreiro (2015) e Vanzolini (2015, 2018). 
mantêm entre si - entre os "humanos" propriamente ditos, kuge, os alto-xinguanos -, ou com outros seres, como os itseke ("espíritos"; hiperseres), os "índios bravos" (ngikogo) ou os brancos.

A depender do contexto e dos envolvidos na transação, os donos dos objetos podem "dar [suas posses] sem esperar nada em troca" (ijatitselü, "compartilhar"; engikombalü, também traduzido como "presentear") ou ainda, "ofertá-los para troca" (akanenügü, - lit. "fazer sentar" [FRANCHETTO; ESPÍRITO SANTO, 2014: 6], em referência à forma como os objetos são ofertados durante os uluki, rituais de troca realizados na região. O termo também é traduzido por meus interlocutores como "vender" ou "trocar". A primeira das ações é aquela esperada de parentes próximos - a forma ideal de circulação de alimentos, sejam eles "tradicionais" ou industrializados -, enquanto a segunda é o que, idealmente, se pratica com afins (com exceção dos cônjuges, com quem há uma expectativa de compartilhamento de bens), parentes considerados distantes e amigos, sejam eles "parentes" ou não. O que distingue as duas ações - ijatitselülengikombalü, de um lado, e akanenügü, de outro - é menos a existência ou não de uma retribuição (já que mesmo no ato de "presentear" há uma expectativa de retorno, ainda que não imediato), mas a ênfase dada em cada uma das ações. Enquanto a troca propriamente dita, marca a distância entre os sujeitos - e, por isso, deve ser evitada entre parentes considerados próximos -, dar algo, sem a expectativa de um retorno imediato, marca as relações de proximidade entre os envolvidos.

Cotidianamente, todo tipo de objetos e ferramentas (que vão desde pequenas tesouras, facões e panelas, passando por motosserras, enfeites, bicicletas e motos) são compartilhados por parentes próximos - especialmente irmãos (uhisuügü- $\mathrm{B}^{24}, \mathrm{Z}$ ), cunhados (uhaumetigü- WB, $\mathrm{ZH}$ ), irmãos e irmãs do cônjuge (upahene - WZ, HB) e parentes de gerações ascendentes (F, M, FM, MM, FF, MF). Da mesma forma, o dinheiro e os objetos industrializados (principalmente aqueles que possuem um alto potencial de produzir desejo nas pessoas) também circulam cotidianamente entre parentes próximos, por meio de empréstimos e/ou "presentes", doações, seja de forma espontânea, seja por meio da "partilha sob demanda" (demand sharing), para usar o conceito descrito por Peterson (1993) e Ewart (2013). Dessa forma, assim que são trazidos para a aldeia esses bens começam a ser cobiçados pelas pessoas, que o pedem ao seu dono. Este se vê, muitas vezes, obrigado a dar ou vender o bem em questão, especialmente quando se trata de pedidos, suscitados pelo desejo (iti; hogu) dos parentes mais próximos.

Isso ocorre porque, para os Kalapalo, uma vontade não controlada ou um desejo não suprido pode levar ao adoecimento e até mesmo à morte, ao produzir um estado de vulnerabilidade, kahujehetil $\ddot{u}^{25}$. Esse estado implica em uma "inadequação entre o desejo e sua satisfação, que torna vulnerável a 'alma-sombra' (akua) da pessoa” (FRANCO NETO, 2010: 36), produzindo uma espécie de "saliência visual" (BARCELOS NETO, 2007: 4) que faz com que a pessoa seja vista por "espíritos" (itseke) e animais que podem provocar seu adoecimento e até

24 Utilizo a notação inglesa para a descrição de relações de parentesco, segundo a qual os marcadores dos kin types são formados pela primeira letra do termo de parentesco em inglês e devem ser lidos da esquerda para a direita. 
mesmo sua morte. Essa situação é particularmente perigosa quando se trata de crianças, pelo fato de não saberem lidar nem controlar direito os desejos e de "quererem mais coisas que os adultos", conforme afirmam os Kalapalo. Cabe, assim, aos pais e parentes mais velhos suprir esses desejos dos mais jovens, sejam eles filhos, netos, sobrinhos ou irmãos mais novos.

As mercadorias, em função de sua grande variedade de cores, luzes, formas e propriedades - as mesmas características que lhes garantem a propriedade de serem identificadas como "coisas de itseke" -, possuem uma grande capacidade de incitar o desejo nas pessoas, o qual, se não suprido, pode provocar o descontrole e as consequências decorrentes dele. Para serem capazes de satisfazer os desejos (seus ou de outrem) por mercadorias, entretanto, as pessoas precisam acessar montantes cada vez maiores de recursos, o que explica a procura cada vez maior pelas políticas de transferência de renda.

\section{Palavras finais}

Se, por um lado, a disponibilidade dos benefícios sociais permite que as pessoas supram seus desejos pelos objetos industrializados, ou pela também desejada escolarização e, ao mesmo tempo, permaneçam morando nas aldeias, sem precisar sair para trabalhar na cidade, por outro lado, seu acesso (que implica no cadastramento, atualização cadastral e saque dos valores) implica na permanência por tempos cada vez mais prolongados na cidade. Esse trânsito mais frequente, por sua vez, gera efeitos muitas vezes não previstos e nem sempre bem avaliados, ao fazer com que as pessoas se distanciem das tarefas domésticas e também de seus parentes. Adicionalmente, mesmo sem precisar morar nas cidades, a satisfação dos desejos pelas mercadorias e pelo "mundo do branco" tem sido acompanhada por um aumento expressivo do que é desejável, aumentando também a necessidade dos recursos e, consequentemente, a frequência com que acabam se deslocando até as cidades. Um ciclo vicioso que parece não mostrar saídas: para a (re)produção do parentesco é cada vez mais necessária a circulação de mercadorias que, para serem adquiridas, exigem a imposição de fraturas (que podem ser muito breves, mas também muito sérias) nas redes de parentesco. Esse processo cria um movimento de mão dupla, de "atração no sentido duplo de atrair e de sentir-se atraído por" (HORTA, 2015), cada vez mais difícil de se manter, na medida em que depende, fundamentalmente, de recursos estatais que já mostram sinais de esgotamento. Somente daqui algum tempo será possível dizer com mais precisão quais serão as consequências que essa eventual impossibilidade de suprir os desejos proporcionará entre meus anfitriões.

Tomando como referência a experiência dos Kalapalo de Aiha com as políticas de transferência de renda, mais especificamente o PBF, busquei mostrar como o desenho universalista desse programa acaba por transformá-lo em uma espécie de rolo compressor das diferenças e desigualdades, "transformando-as em mera desigualdade social" (BONILLA; CAPIBERIBE, 2015: 7). Ao restringir a situação de pobreza a uma condição exclusivamente monetária, os governantes se colocam ao lado do dito "desenvolvimento", desconsiderando as especificidades dos modos de 
vida dos povos indígenas e também de outros povos e comunidades que dependem da relação com a terra, as florestas, os rios. Não há dúvidas dos avanços que o acesso à renda possibilita, como bem apontei ao longo do texto. Todavia, a distribuição de renda sem a garantia das condições fundamentais para a produção e reprodução de uma vida considerada boa, ou seja, uma vida ao lado dos parentes, parece sem sentido para os Kalapalo.

\section{Referências bibliográficas}

AHLERT, M. A "precisão" e o "luxo": usos do benefício do Programa Bolsa Família entre as quebradeiras de coco de Codó (MA). Política \& Trabalho, v. 38, p. 69-86, 2013.

ALBERT, B.; RAMOS, A. R. (Eds.). Pacificando o branco: cosmologias do contato no Norte-Amazônico. São Paulo: Editora UNESP, 2002.

ÁVILA, M. P. Que pensam as beneficiárias do Bolsa Família? Política \& Trabalho, v. 38, p. 105-122, 2013.

BANIWA, G. L. To Dominate the System and Not to be Dominated by it. Poverty in Focus, International Policy Center For Inclusive Growth, n. 17, p. 6-8, 2009.

BARCELOS NETO, A. Catálogo da exposição "Com os índios Wauja. Objectos e personagens de uma colecção amazónica”. Lisboa: Museu Nacional de etnologia, 2004.

BARCELOS NETO, A. Wĩtsixuki: desejo alimentar, doença e morte entre os Wauja da Amazônia meridional. Journal de la Société des Américanistes, v. 93, n. 1, p. 73-95, 2007.

BONILLA, O.; CAPIBERIBE, A. Isolados ou cadastrados: os índios na era desenvolvimentista. Revista DR, n. 1, p. $1-7,2015$.

BRASIL. Pesquisa Nacional por Amostra de Domicílios - 2011 (IBGE). Rio de Janeiro: IBGE, 2012. Disponível em: <ftp://ftp.ibge.gov.br/Trabalho_e_Rendimento/Pesquisa_Nacional_por_Amostra_de_Domicilios_anual/2011/ Sintese_Indicadores/sintese_pnad2011.pdf>.

BRASIL; MDS. Portaria GM/MDS n 341 de 07 de outubro de 2008. Brasília: MDS, 2008. Disponível em: <http:// www.mds.gov.br/bolsafamilia/legislacao-1/portarias/2008/Portaria_de_Ingresso_de_Familias_no_PBF_no_341_-com_as_alteracoes_da_Portaria_no_617-_site-1.pdf>

BRASIL; MDS. Guia de cadastramento de famílias indígenas. 3a edição ed. Brasília: MDS, 2015. 
BRASIL; MDS. Manual do entrevistador. 3a edição ed. Brasília: MDS, 2016.

BRASIL; MDS. Bolsa Família. 2017. Disponível em: < http://www.mds.gov.br/assuntos/bolsa-familia $>$. Acesso em: 7 abr. 2017.

CAMPELLO, T. Uma Década Derrubando Mitos e Superando Expectativas. In: CAMPELLO, T.; NERI, M. C. (Eds.). Programa Bolsa Família: uma década de inclusão e cidadania. Brasília: Ipea, 2013. p. 15-24.

COSTA, L. Alimentação e comensalidade entre os Kanamari da Amazônia Ocidental. Mana, v. 19, n. 3, p. 473-504, 2013.

COSTA, L. Fabricating Necessity: Feeding and Commensality in Western Amazonia. In: BRIGHTMAN, M.; FAUSTO, C.; GROTTI, V. (Eds.). Ownership and nurture: studies in native Amazonian property. New York, Oxford: Berghahn Books, 2016. p. 81-109.

CUNHA, R. Transferência de renda com condicionalidade: a experiência do Programa Bolsa Família. In: BRASIL; MDS (Eds.). Concepção e gestão da proteção social não contributiva no Brasil. Brasília: MDS, UNESCO, 2009.

DELEUZE, G.; GUATTARI, F. O anti-Édipo: capitalismo e esquizofrenia 1. São Paulo: 34, 2010.

DOLE, G. Ownership and exchange among the Kuikuru indians of Mato Grosso. Revista do Museu Paulista, v. X, p. $125-142,1958$.

EWART, E. Demanding, giving, sharing, and keeping: Panará ideas of economy. The Journal of Latin American and Caribbean Anthropology, v. 18, n. 1, p. 31-50, 2013.

FAUSTO, C. Donos demais: maestria e domínio na Amazônia. Mana, v. 14, p. 329-366, 2008.

FERGUSON, J. Development. In. BARNARD, Alan; SPENCER, Jonathan. Encyclopedia of social and cultural anthropology. London; New York: Routledge, 2002.

FISZBEIN, A. Conditional cash transfers : reducing present and future poverty. Washington DC: The International Bank for Reconstruction and Development / The World Bank, 2009.

FONSECA, A. Los sistemas de protección social en América Latina: Un análisis de las transferencias monetarias condicionadas. Seminario Internacional sobre Transferencia Condicionada de Ingresos y Seguridad Alimentaria. Anais... Santiago de Chile: Oficina Regional de FAO, 2006. Disponível em: $<$ http://www.oda-alc.org/documentos/1341944469.pdf>. Acesso em: 20 mar. 2017 
FRANCHETTO, B. A comunidade indígena como agente da documentação lingüistica. Revista de Estudos e Pesquisas, FUNAI, v. 4, n. 1, p. 11-32, 2007.

FRANCHETTO, B.; ESPÍRITO SANTO, J. L. (Eds). Dicionário Kuikuro - Português. Rio de Janeiro: (não publicado), 2014.

FRANCO NETO, J. V. Xamanismo Kalapalo e Assistência Médica no Alto Xingu: estudo etnográfico das práticas curativas. Campinas: Unicamp, 2010.

FRASER, N. Social Justice in the Age of Identity Politics: Redistribution, Recognition, and Participation. In: FRASER, N.; HONNETH, A. (Eds.). Redistribution or Recognition? New York;London: Verso, 2003. p. 7-109.

GORDON, C. Economia selvagem : ritual e mercadoria entre os índios Xikrin-Mebêngôkre. 1a. ed. São Paulo, Rio de Janeiro: Editora UNESP/ISA/NUTI, 2006.

GOW, P. An Amazonian Myth and Its History. Oxford: Oxford University Press, 2001.

GUERREIRO, A. Ancestrais e suas sombras. Campinas: Editora da Unicamp, 2015.

HORTA, A. Indígenas em Canarana: notas citadinas sobre a criatividade xinguana. Anales del 55 Congresso Internacional de Americanistas. Anais... San Salvador: 2015

HORTA, A. Indígenas em Canarana: notas citadinas sobre a criatividade parque-xinguana. Revista de Antropologia, v. 60, n. 1, p. $216-241,2017$.

HORTA, A. Relações indígenas na cidade de Canarana (MT). Tese de Doutorado - PPGAS, Museu Nacional, UFRJ, Rio de Janeiro, RJ, 2018.

JANUZZI, P.; PINTO, A. R. Bolsa Família e seus impactos nas condições de vida da população brasileira. In: CAMPELLO, T.; NERI, M. C. (Eds.). Programa Bolsa Família : uma década de inclusão e cidadania. Brasília: Ipea, 2013. p. 179-192.

KOPENAWA, D.; ALBERT, B. A queda do céu. São Paulo: Companhia das Letras, 2015.

NOVO, M. Esse é o meu patikula: uma etnografia do dinheiro e outras coisas entre os Kalapalo de Aiha. Tese de doutorado - PPGAS, UFSCar, São Carlos, SP, 2018.

PERRONE-MOISÉS, B. Festa e Guerra. São Paulo: USP, 2016. 
PETERSON, N. Demand Sharing: Reciprocity and the Pressure for Generosity among Foragers. American Anthropologist, v. 95, p. 860-874, 1993.

PIEDADE, A. O Canto do Kawoká: Música, cosmologia e filosofia entre os Wauja do Alto Xingu. Tese de Doutorado - PPGAS, UFSC, Florianópolis, SC, 2004.

PIRES, F. F. A casa sertaneja e o Programa Bolsa Familia. Política \& Trabalho, v. 27, p. 1-12, 2009.

PIRES, F. F. Child as family sponsor: An unforeseen effect of Programa Bolsa Familia in northeastern Brazil. Childhood, v. 21, n. 1, p. 134-147, 2013a.

PIRES, F. F. Do ponto de vista das crianças: uma avaliação do Programa Bolsa Família. Sumários executivos SAGI/ MDS, 2013b.

SOARES, F. V. et al. Programas de transferência de renda no Brasil: impactos sobre a desigualdade. Texto para discussão - IPEA, n. 1228, p. 7-40, 2006.

SOARES, F. V.; RIBAS, R. P.; OSÓRIO, R. G. Evaluating the Impact of Brazil's Bolsa Família: Cash Transfer Programmes in Comparative Perspective. IPC evaluation note, n. 1, p. 1-11, 2007.

VANZOLINI, M. A flecha do ciúme: O parentesco e seu avesso segundo os Aweti do Alto Xingu. São Paulo: Terceiro Nome, 2015.

VANZOLINI, M. O feitiço e a feitiçaria capitalista. Revista do Instituto de Estudos Brasileiros, n. 69, p. 324-337, 2018.

VERDUM, R. Estudos etnográficos sobre o Programa Bolsa Família entre povos indígenas. Brasília: MDS, 2016.

VIENNE, E. DE; ALLARD, O. Pour une poignée de dollars? Cahiers des Amériques latines, v. 48-49, p. 126-165, 2007.

VIVEIROS DE CASTRO, E. Perspectival anthropology and the method of controlled equivocation. Tipiti: Journal of the Society for the Anthropology of Lowland South America, v. 2, n. 1, p. 2-22, 2004.

VIVEIROS DE CASTRO, E. B. Indivíduo e sociedade no Alto Xingu: os Yawalapiti. Dissertação de mestrado PPGAS, Museu Nacional, UFRJ, Rio de Janeiro, RJ, 1977. 